hind the larynx. Thinking that possibly the growth, by its size and location, mechanically prevented the entrance of food, I determined to remove it. This I had no difficulty in accomplishing, using the galvano-cautery snare, removing it in four pieces, there being neither pain nor hæmorrhage during the operation. There was no reaction of any consequence subsequently. On attempting to pass a bougie into the cesophagus, I found a stricture at the upper part, although deglutition had been somewhat facilitated by the removal of the growth.

Microscopic examination revealed the fact that the growth was a ring-shaped carcinoma. After this time I dilated the stricture about every five days and twice each day I passed the stomach tube, giving the patient each time nearly a quart of milk, together with two eggs. Sometimes peptones were added instead of eggs, and for the last two months an ounce of brandy was given with each feeding, at the patient's request. For a short time the patient gained somewhat in weight, and quite materially in strength, going about the city freely and seemingly happy, and he said free from pain. At home he took some coffee and occasionally a little soup or broth. This treatment was continued for several months, when the patient died.

One interesting and troublesome feature of the case might be mentioned. From first to last it was impossible to introduce the stomach tube without the aid of the laryngoscope, thus necessitating personal care of the patient.

There was no return of the growth in the laryngeal cavity but the extension was downward.

70 State Street.

\section{FRACTURE OF THE THYROID CARTILAGE.}

BY GEORGE L. MORGENTHAU, M.D., OF CHICAGO.

ASSISTANT AT PROFESSOR SCHNITZLER'S POLICLINIC FOR DISEASES OF THE THROAT AND CHEST, VIENNA.

Since Arbuthnot Lane ${ }^{3}$ (1885) drew the attention of the profession to the frequency of fractures of the hyoid bone and larynx, several cases have been reported which tend to confirm his statement, that these fractures sometimes produce such light symptoms that they can be overlooked. Formerly, the prognosis was considered much graver. Gurlt ${ }^{2}$ had (in I864) collected 68 cases, of which 47 ended fatally, and only 21 recovered. Even excluding those in which the injury was caused by an attempt on the patient's life, or where some additional accident complicated matters, 2 I died, and but $I_{3}$ recovered. Fischer ${ }^{3}$ pronounces every

I Arbuthot Lane, British Med. Journal, March, 1885 1864 .

Gurlt, Handbuch der Lehre von den Knochenbrichen, ii Teil.

Fischer, Deutsche Chirurgie, Lief. 34 fracture of the larynx serious. Later observers, however, contributed statistics which are more encouraging. The most recent publication, by Sakolowski, ${ }^{4}$ describes a severe case with recovery. In it will be found a summary of the literature on the subject, statistics, etc. Although the case I had occasion to observe is an uncomplicated one, or rather because it shows how exceedingly light the symptoms resulting from a fracture of the thyroid cartilage can be, I think it worthy of publication.

The patient, a fairly intelligent, robust artisan of about 40, came to Professor Schnitzler's department in the Wiener Allgemeine Poliklinik. on account of hoarseness. On being questioned how long this had troubled him, he said that some three months ago, while bending over a balustrade, he was struck on the back of the head by a descending, heavily loaded elevator. His neck was pressed between the lift and the bar. He was immediately attacked by a coughing spell, expectorated a little pure blood, and became aphonic. There was no pain, but the swelling about the neck induced him to go home and make applications. The next day he could go to work again, hoarseness being the only reminder of yesterday's accident. It was the hoarseness on account of which he came to the Policlinic, not having found it necessary to consult any physician meanwhile.

While inspection revealed nothing abnormal in the anterior part of the neck, upon applying the finger to the angle of the thyroid cartilage, the left ala receded. By rubbing the two fragments together, distinct crepitus could be heard and felt. Further palpation showed that the left wing of the thyroid cartilage was fractured longitudinally, the line being slightly irregular, and about $1 / 8$ of an inch from the angle of the cartilage. All other parts, especially the hyoid bone and cricoid cartilage, were examined carefully, but appeared unharmed. The condition of the interior of the larynx was as follows: The epiglottis was omega-shaped, slightly overhanging. Both ventricular bands were much swollen, but did not look angry. The vocal cords could not be seen. Even in phonation, only a little portion of the posterior ends could be perceived. During the act of phonation the ventricular bands approximated, apparently producing the hoarse voice. An accurate opinion of the lesions in the larynx cannot be formed. The mucous membrane must have been lacerated, since the accident was immediately followed by hæmoptysis. The rent in the membrane, however, could not have been long or deep, or emphysema would have set in. According to statistics, there is emphysema in most of the cases, sometimes extending to the extremities. Possibly, also, the anterior attachment of the vocal

\footnotetext{
4 Sakolowski, Berl. Klin. Woch, No. 40, 1890.
} 
cords was severed, and they could not be seen because they could not contract, not only because they were bidden by the ventricular bands. Another interesting question (also from a medicolegal point of view in cases of assault), is why, in this case, the line of fracture was vertical, and in or near the centre. Gurlt's experiments demonstrate that vertical fractures are possible when the larynx is compressed antero-posteriorly, as in this case. Possibly, ossification in the cartilaginous tissue had advanced to just the line of fracture. And the absence of the youthful elasticity-due in turn to the deposit of bony matter -is a predisposing moment (Hoffmann ${ }^{5}$ ). To be sure, the elasticity is not so great as to protect the larynx against every injury by external force. Figures show that youthful individuals are not at all immune against fracture of the larynx, although partial ossification predisposes to injuries. As this patient is over 40 years, ossification has undoubtedly begun. According to Patenko's ${ }^{6}$ observations, the elasticity is not diminished before the thirtieth year, and ossification varies very much, also, in regard to the region where it commences, and to its extension. Another explanation applicable in the present case is offered by Gurlt. When the line of fracture is to one side, this might be due to the suture which is formed by the ala of the thyroid and a narrow, thin cartilage sometimes found between the two wings.

The only indication in this case, at the time the patient came to the Policlinic, might have been the alleviation of the hoarseness. The fracture caused him no inconvenience excepting the hoarseness, which did not hinder him in his work. We could not, therefore, in conscience advise him to undergo an operation, although the case might be considered well adapted for sutures. There was no vestige, here, of the formation of a bony callus after three months, though Lane demonstrated a specimen in which bony union had taken place. Perhaps the increased irritation by the wire sutures might have proved a favorable factor in bringing about such a result. Even fibrous union would justify an operation in some cases. As to the advisability of using sutures, the opinions of surgeons are divided. Fischer reports that all kinds of wounds and injuries in the upper air passages have healed as well without sutures as with them.

Generally, tracheotomy has been performed when the surgeon was called in shortly after the accident. Threatening dyspnoa will make this operation necessary in the majority of cases. Besides, in fracture of the cricoid cartilage, the canula tends to immobilize the fragments (Clar$\left.\mathrm{ac}^{7}\right)$. Both indications might be met, in fracture

\footnotetext{
5 Hoffmann, Wiener Med. Woch., Nos. 44 and $45,1886$.
6 Patenko, Vierteljahschr. f. gerichtb. Med. von Fulenberg, Bd. xli. 7 Clarac, Gaz. des Hôp., September, Isgo. (Int. Centralbl. f Laryngologie, etc.)
}

of the thyroid cartilage, by O'Dwyer's permanent tubes. Intubation ought certainly to be tried in appropriate instances. Adaptation of the fragments will often present great difficulties, either when done from without through the tracheotomy wound or an incision, or possibly from above by aid of forceps. Complete rest, ice-bags on the wound, and vapors, are certainly of great benefit. The case described proves that tracheotomy is not always necessary. After only a day's rest the patient returned to work, without ever experiencing pain, or any inconvenience excepting hoarseness.

Vienna, July I, I8gr.

\section{A BRIEF COMMUNICATION ON NASAL VIBRATION (MASSAGE) WITH REPOR'T OF CASES. \\ BY NORVAL H. PIERCE, M.D., OF LONDON, ENG.}

At the Tenth International Medical Congress a paper was read before the Laryngological Section, which at once attracted attention, first, because it sought to introduce a novelty into our therapeusis; secondly, because it had for its scope and promise the cure of a class of diseases which have been regarded as nearly or altogether incurable, I refer to Dr. Brown's paper on Vibratory Massage of the Nose, ${ }^{1}$ etc.

In order to refresh the memory of the reader I will take the liberty of presenting an extract translation of the above mentioned contribution.

The two massage movements employed are known according to Dr. Kellgrew (London) as effleurage and vibration.

By effleurage is meant a stroking movement superficial or deep, the force of which varies from a scarcely perceptible touch to distinct pressure.

By vibration is meant a light, rapid trembling movement, having its origin in the elbow joint and which is transmitted by the palmer ends of the fingers to the point of operation. The motions occurring in the relaxed wrist joint are $a b$. duction and adduction, while the hand itself remains in uninterrupted contact with the surface operated upon. The whole procedure is characterized by a lightness, rapidity, and elasticity of touch. The number of vibratory movements varies from 200 to 300 per minute.

In order to apply this treatment to the nasal cavities, a copper sound is necessary. The one recommended measures twenty $\mathrm{cm}$. in length, and has a diameter at the larger end of two mm. The end which is introduced into the nose is finished with a ribbed head to which cotton may be attached. This cotton may be immersed in

Massage, beziehungsweise, Vibrationen, der Schleimhaut de Nase, der Nasentachenrauns und des Rachens. Dr. Michael Bram, Triest, Destreich. 